\title{
Epiploic appendagitis
}

\author{
Philippe Leclercq MD, Laurent Dorthu MD
}

Previously published at www.cmaj.ca

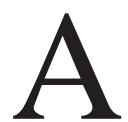

33-year-old man was admitted to the emergency department with a rapid onset of left flank pain.

On examination, he had a temperature of $38.2^{\circ} \mathrm{C}$ and tenderness in the left lower quadrant with muscle guarding. His leukocyte count and C-reactive protein were moderately elevated. Computed tomography of the abdomen (Figure 1) showed an oval-shaped, paracolic mass with the density of fat. A diagnosis of epiploic appendagitis was made. $\mathrm{He}$ was given a one-week course of ibuprofen, and recovered completely. He had no recurrence of the pain during two years of follow-up.

Epiploic appendages are small, fat-filled, serosa-covered structures located on the antimesenteric surface of the colon. These structures are usually $0.5-$ to $5-\mathrm{cm}$ long and 1- to 2-cm thick, and hang into the peritoneal cavity. Although the total number of epiploic appendages on the colon is about 100 , the size and number increase in the lower abdominal quadrants $(57 \%$ are located on the sigmoid colon and $26 \%$ on the ileocecum) ${ }^{1,2}$ Epiploic appendages have no known function. Vascularization of an appendage is provided by two arteries and one vein. In the case of torsion, the venous component is affected first with subsequent inflammation.

Primary epiploic appendagitis caused by torsion is distinguished from secondary appendagitis, which can occur in patients with pericolic inflammatory fluid, as in colitis. ${ }^{2}$ Other proposed causes are lymphoid hyperplasia or bacterial invasion secondary to a deep abdominal infection (e.g., diverticulitis, appendicitis or cholecystitis) making the coexistence of these pathologies possible..$^{1,3}$ The prevalence is unknown because most cases are self-limited. ${ }^{4}$ It has a peak incidence in the fourth and fifth decades but can occur at any age, with a slightly higher frequency in middle-aged men. ${ }^{1}$

Patients present with nonspecific, acute pain in the abdomen, predominantly in the lower quadrants. The symptoms mimic those of acute appendicitis or diverticulitis.

From the Department of Gastroenterology (Leclercq), Centre Hospitalier Universitaire de Liège, Hôpital du Sart-Tilman, Liège, and the Department of Radiology (Dorthu), Centre Hospitalier Peltzer La Tourelle, Verviers, Belgium

CMAJ 2010. DOI:10.1503/cmaj.090791
Guarding is reported in about half of patients and low-grade fever is seen in a minority of patients. ${ }^{2}$ Abdominal ultrasonography can show nonspecific findings such as an oval hyperechoic mass surrounded by a hypoechoic rim, without Doppler flow. The pathognomonic appearance on computed tomography is typically a $1-$ to $4-\mathrm{cm}$ oval-shaped, fat-density lesion with an enhancing rim adjacent to the colon, thickened visceral peritoneal lining, and periappendaceal fat stranding, ${ }^{5}$ as seen in our patient.

Epiploic appendagitis is usually a self-limiting condition that can be managed conservatively with oral anti-inflammatory medications. ${ }^{3}$ Complications such as secondary abscess or intestinal occlusion are uncommon. ${ }^{3.5}$

This article has been peer reviewed.

Competing interests: None declared.

\section{REFERENCES}

1. Ozdemir S, Gulpinar K, Leventoglu S, et al. Torsion of the primary epiploic appendagitis: a case series and review of the literature. Am J Surg 2010;199:453-8.

2. Sangha S, Soto J, Becker J, et al. Primary epiploic appendagitis: an underappreciated diagnosis. A case series and review of the literature. Dig Dis Sci 2004;49:347-50.

3. Bonnefoy S, Corberand D, Sinayoko L, et al. Epiploic appendagitis: report of a case [article in French]. Gastroenterol Clin Biol 2008;32:1092-4.

4. Ammar H, Looney SC, Malani A. Epiploic appendagitis. Lancet 2009;373:2054

5. Singh AK, Gervais D, Hahn P, et al. Acute epiploic appendagitis and its mimics. Radiographics 2005;25:1521-34. 